\title{
Perhadliran dalam Sakramen Perjamuan Kudus di Gereja Protestan Maluku
}

\author{
Sharon Michelle 0. Pattiasina \\ Gereja Protestan Maluku, Ambon \\ michellepattiasina1013@gmail.com
}

\begin{abstract}
The article aims to analyze the meaning of perhadliran in the Sacrament of Holy Communion in the Protestant Church of Maluku. This study using qualitative methods with the techniques used are interviews and literature studies. In the study, data was obtained that the Protestant Church of Maluku did not have a clear historical background regarding the use term of the perhadliran. However, perhadliran was carried out by the Protestant Church of Maluku with the aim of preparing themselves before the Holy Communion was held. The Protestant Church of Maluku interpreted the perhadliran as a process of self-prepation, but some interpreted it as a means of confession, it is required to answer the four questions of the perhadliran. Based on the research data above, it is found that the perhadliran has three meanings, namely the meaning of self-preparation, the meaning of recognition, and the meaning of the agreement.
\end{abstract}

Keywords: holy communion; perhadliran; Protestant church of Maluku; sacrament

\begin{abstract}
Abstrak: Artikel ini bertujuan menganalisis makna perhadliran dalam sakra-men perjamuan kudus di Gereja Protestan Maluku (GPM). Penelitian ini menggunakan metode kualitatif dengan teknik yang dipakai ialah wawancara dan studi kepustakaan. Dalam penelitian, diperoleh data bahwa GPM tidak me-miliki latar belakang historis yang jelas terkait penggunaan istilah perhadliran. Namun, perhadliran dilakukan GPM dengan tujuan untuk persiapan diri sebe-lum Perjamuan Kudus dilaksanakan. GPM memaknai perhadliran sebagai proses persiapan diri, namun sebagian memaknai se-bagai sarana pengakuan dosa, karena di dalam ibadah perhadliran anggota jemaat diharuskan menjawab empat pertanyaan perhadliran. Berdasarkan data-data peneli-tian di atas maka ditemukan bahwa perhadliran memiliki tiga makna yaitu makna per-siapan diri, makna pengakuan dan makna perjanjian.
\end{abstract}

Kata kunci: Gereja Protestan Maluku; perhadliran; perjamuan kudus; sakramen

$\begin{array}{llll}\text { Article History : } & \text { Received: 16-07-2019 Accepted: 20-12-2019 }\end{array}$

\section{Pendahuluan}

Gereja Protestan Maluku bersama Gereja Protestan Sedunia memiliki dua sakramen yang sering dilaksanakan, yaitu sakramen Baptisan Kudus dan sakramen Perjamuan Kudus. Menurut Calvin, sakramen Baptisan Kudus adalah tanda bahwa kita telah diterima masuk ke dalam persekutuan gereja, supaya setelah kita ditanamkan di dalam 
Kristus maka kita adalah anak-anak Allah. ${ }^{1}$ Gereja Protestan Maluku memahami sakramen Baptisan Kudus sebagai tanda bahwa seseorang mengalami penyucian dosa, dimeteraikan sebagai Anggota Tubuh Kristus dan sebagai pewaris Kerajaan Allah. ${ }^{2}$ Dengan demikian, pelaksanaan sakramen Baptisan Kudus dapat mengokohkan iman kita bahwa setiap anak yang dibaptis akan memperoleh janji-janji keselamatan dari Allah. Dalam pelaksanaan sakramen Baptisan Kudus, seluruh warga jemaat tidak diikutsertakan untuk mempersiapkan diri. Umumnya, orang tua dan orang tua baptis atau papa dan mama serani yang perlu mempersiapkan diri melalui proses penggembalaan yang dilakukan oleh pendeta dan majelis jemaat. Proses penggembalaan dilakukan tiga sampai empat hari sebelum Baptisan Kudus dilaksanakan. Dalam proses penggembalaan, orang tua dari yang dibaptis dan para saksi diarahkan oleh pendeta dan majelis jemaat agar mampu melaksanakan kewajiban mereka dalam membina dan membimbing anak yang dibaptis sesuai ajaran Yesus. Selain Baptisan Kudus, GPM juga melaksanakan sakramen Perjamuan Kudus.

Tulisan ini menyoroti tentang ibadah persiapan sebelum mengikuti sakramen perjamuan kudus di GPM yang disebut sebagai ibadah perhadliran. Setelah menelusuri tentang tulisan-tulisan terkait GPM, penulis hanya menemukan satu tulisan yang menyinggung konsep perhadliran dengan judul Tantangan Gereja-gereja Calvinis di Indonesia oleh Agustinus M. L. Batlajery. Minimnya tulisan tentang perhadliran disebabkan oleh GPM belum menelusuri lebih dalam terkait sejarah perhadliran dan bahkan dipengaruhi oleh tradisi oral yang dianut masyarakat Maluku selama ini.

Sakramen Perjamuan Kudus yang dilaksanakan oleh GPM merupakan bentuk peringatan dan penghayatan akan peristiwa pengorbanan Yesus di kayu salib. Setiap anggota jemaat yang turut mengambil bagian dalam perayaan sakramen Perjamuan Kudus haruslah mengaku bahwa melalui peristiwa pengorbanan Yesus di kayu salib, Kristus telah mengambil jalan yang harus ditempuh oleh kita sendiri. ${ }^{3}$ Dalam pelaksanaan, sakramen Perjamuan Kudus berbeda dengan sakramen Baptisan Kudus. Setiap orang yang memberikan diri untuk terlibat di dalam perayaan sakramen Perjamuan Kudus dapat berarti bahwa mereka mau untuk bersekutu dengan Tuhan dan juga dengan orang-orang percaya. ${ }^{4}$ Oleh sebab itu, sakramen Perjamuan Kudus sangat memerlukan kesiapan dari seluruh anggota jemaat yang telah sidi. ${ }^{5}$ Sebagai tanda kesiapan dan kesedian mengikuti sakramen Perjamuan Kudus, setiap warga gereja yang telah sidi diminta menghadiri ibadah Minggu yang di dalamnya dilaksanakan ritus awal perjamuan kudus, yaitu perhadliran. Dengan kata lain, perhadliran merupakan bagian dari ibadah persiapan Perjamuan Kudus yang umumnya dilaksanakan seminggu

\footnotetext{
${ }^{1}$ Yohanes Calvin, Institutio: Pengajaran Agama Kristen (Jakarta: BPK Gunung Mulia, 2008), 281.

2 Himpunan I Liturgi Gereja Protestan Maluku (Ambon: Sekretariat Umum Gereja Protestan Maluku, 2011), 26.

${ }^{3}$ Himpunan I Liturgi Gereja Protestan Maluku, 37.

${ }^{4}$ R. Soedarmo, Ikhtisar Dogmatika (Jakarta: BPK Gunung Mulia, 2009), 246.

${ }^{5}$ Elifas T. Maspaitella, Perjamuan Kudus GPM, Kutikata Blog, 26 April 2011, diakses pada 3 Februari 2018, http://kutikata.blogspot.co.id/2011/04/perjamuan-kudus-gpm.html.
} 
sebelum pelaksanaan Perjamuan Kudus oleh GPM. Saat perhadliran dilaksanakan seluruh anggota jemaat yang telah sidi diminta untuk berdiri dan menjawab empat pertanyaan sebagai tanda pengakuan iman dan kesediaan mereka untuk mengikuti perjamuan kudus.

Adapun pertanyaan-pertanyaan dimaksud perhadliran, yaitu:

1. Adakah saudara-saudari percaya dengan segenap hati, bahwa pengajaran yang benar dan sempurna yang membina kepada keselamatan berdasarkan firman Allah yang semuanya hanya terdapat di dalam Alkitab?

2. Adakah dengan segenap hati saudara-sudari percaya, bahwa justru oleh karena dosa maka kita patut dimusnahkan oleh Allah dan sebab itu kita harus menyesali akan diridiri kita?

3. Adakah saudara-saudari mengaku, bahwa berdasarkan kasih Allah yang tidak berhingga, sudahlah Ia mengaruniakan kita anakNya yang tunggal Tuhan Yesus Kristus yang dengan rela telah memecahkan tubuh-Nya dan menumpahkan darah-Nya khusus untuk pengampunan dosa-dosa kita, pengorbanan mana patut disambut dengan hati yang beriman?

4. Adakah saudara-saudari berniat dengan hati yang tulus ikhlas sesuai panggilan kita berdasarkan Baptisan Kudus dan Pengakuan Iman, untuk menyerahkan hidup dipengaruhi oleh roh kudus agar bertambah-tambah di dalam kasih, iman dan pengharapan serta hidup dalam persekutuan yang benar, sebagaimana patut bagi segala orang percaya? ${ }^{6}$

Dalam pelaksanaan perhadliran, tidak semua anggota jemaat yang telah sidi benarbenar berniat untuk mengikuti Perjamuan Kudus.

Berdasarkan temuan penelitian, ada anggota jemaat yang telah sidi tetapi tidak berdiri saat perhadliran, disebabkan karena alasan pribadi dan menyadari bahwa sedang melakukan kesalahan atau dalam kondisi tidak layak dengan berbagai kasus yang sementara mereka alami. Setelah mengikuti perhadliran, anggota jemaat yang telah bersedia untuk mengikuti Perjamuan Kudus dituntut untuk mempersiapkan diri seperti lebih berhati-hati dalam berbicara dan bertindak sehingga masa-masa persiapan menjelang Perjamuan Kudus dapat dimaknai dengan baik. Menurut beberapa anggota gereja, tidak semua orang bertindak dengan baik selama masa-masa persiapan menjelang Perjamuan Kudus. Beberapa diantaranya mengisi masa-masa persiapan dengan perselingkuhan, seks bebas, minuman keras, mengucapkan kata-kata makian, dan berjudi. Perilaku-perilaku ini secara tidak langsung mengindikasikan bahwa sakramen Perjamuan Kudus tidak lagi dianggap sebagai sesuatu yang sakral.

Masa-masa persiapan perayaan Perjamuan Kudus tidak lagi dimaknai sebagai bentuk persiapan diri demi mengokohkan nilai-nilai Kristiani. Penghayatan akan peristiwa pengorbanan Yesus seakan dicemarkan dengan perilaku-perilaku yang tidak baik. Berdasarkan latar belakang di atas, penulis melihat bahwa fenomena ini perlu diteliti lebih lanjut tentang bagaimana Gereja Protestan Maluku memaknai perhadliran dalam Sakramen Perjamuan Kudus? Penelitian ini dilakukan dengan tujuan untuk mendes-

${ }^{6}$ Himpunan I Liturgi Gereja Protestan Maluku, 124. 
kripsikan dan menganalisis makna perhadliran dalam Sakramen Perjamuan Kudus di Gereja Protestan Maluku.

\section{Metode Penelitian}

Secara umum, metode penelitian dapat didefinisikan sebagai suatu kegiatan ilmiah yang terencana, terstruktur, sistematis dan memiliki tujuan tertentu. Jenis penelitian yang dilakukan adalah deskriptif dengan menggunakan metode kualitatif. Metode kualitatif sebagai prosedur penelitian yang menghasilkan data deskriptif berupa kata-kata tertulis atau lisan dari orang-orang dan perilaku yang dapat diamati. ${ }^{7}$ Metode kualitatif yang didasarkan pada deskripsi yang jelas dan detail menghasilkan penyajian atas temuan akan sangat kompleks, rinci dan komprehensif sesuai dengan fenomena yang terjadi. ${ }^{8}$

Penelitian ini dilakukan di Jemaat GPM Galala-Hative Kecil khususnya di kalangan pemuda gereja. Dalam penelitian ini, teknik pengumpulan data yang digunakan berupa wawancara yang mendalam (deep interview) dan studi kepustakaan. Wawancara merupakan suatu proses interaksi dan komunikasi verbal dengan tujuan untuk mendapatkan informasi penting yang diinginkan. Informan yang akan diwawancarai ialah Sinode GPM, pendeta jemaat dan pemuda gereja. Selain wawancara, penulis juga akan melakukan studi kepustakaan untuk memperoleh data melalui teori-teori para ahli yang dapat membantu penulis untuk menganalisis tentang makna Perhadliran dalam sakramen Perjamuan Kudus.

\section{Pembahasan}

\section{Tinjauan Historis Perayaan Sakramen Perjamuan Kudus}

Sakramen baptisan dan perjamuan kudus yang telah ditetapkan oleh Gereja Protestan merupakan ritual yang unik dari pelayanan gereja. Akan tetapi, sakramen ini tidak diciptakan secara langsung oleh gereja melainkan diambil dari komunitas Perjanjian Lama, terutama sakramen Perjamuan Kudus. Sakramen Perjamuan Kudus ini bermula dari perayaan Perjamuan Paskah yang dilakukan oleh orang-orang Yahudi.

Perjamuan Paskah (pesakh) dilaksanakan pada hari ke-14 dalam bulan Nisan yang menurut kalender Yahudi terdapat pada bulan Maret atau awal April. ${ }^{9}$ Paskah dalam tradisi Yahudi merupakan perayaan pembebasan bangsa Israel dari perbudakan Mesir. Orang Israel diperintahkan untuk menyembelih anak dan mengoleskan darahnya pada bagian muka pintu dengan tujuan agar orang Israel terbebas dari kematian anak sulung laki-laki. ${ }^{10}$ Perayaan Perjamuan Paskah ini dimaknai sebagai perayaan peringatan akan keluaran yang berfungsi sebagai sumber inspirasi dan lambang pengharapan. ${ }^{11}$

\footnotetext{
${ }^{7}$ Lexy J. Moleong, Metodologi Penelitian Kualitatif (Bandung: Remaja Rosdakaria, 1998), 3.

${ }^{8}$ Noman K. Denzin dan Yonna S. Lincoln, The Sage Handbook of Qualitative Research I (Yogyakarta: Pustaka Pelajar, 2011), xviii.

${ }_{9}^{9}$ A. Munthe, Tema-tema Perjanjian Baru (Jakarta: BPK Gunung Mulia, 2006), 9.

10 Peter Walker, In The Steps OfJesus (Yogyakarta: Kanisius, 2010), 156.

${ }^{11}$ C. J. Den Heyer, Perjamuan Tuhan: Studi mengenai Paskah dan Perjamuan Kudus bertolak dari penafsiran dan Teologi Alkitabiah (Jakarta: BPK Gunung Mulia, 1994), 32.
} 
Peringatan akan pembebasan bangsa Israel dari Mesir menuntut adanya suatu kesadaran baru akan rahmat Tuhan dan suatu kesetiaan baru terhadap perjanjian Tuhan yang akan dibuatNya setelah pembebasan tersebut. ${ }^{12}$ Selain itu, Perayaan Perjamuan Paskah juga dirayakan dengan maksud untuk membarui sikap dan pengucapan syukur dengan penuh sukacita. ${ }^{13}$ Harls Evan R. Siahaan menyarankan agar perayaan Paskah dapat menjadi cara untuk mengajarkan nasionalisme gereja. ${ }^{14}$

Perayaan Perjamuan Paskah Israel oleh Gereja Protestan diambil alih menjadi salah satu sakramen gereja untuk peringatan akan kematian Kristus sebagai bentuk peringatan keluaran bangsa Israel dari perbudakan Mesir. Gereja mengambil bagian di dalamnya karena gereja memahami anak domba yang disembelih pada saat perayaan Perjamuan Paskah Israel sama seperti dengan Kristus yang tersalib. Dalam Injil Yohanes, peristiwa kematian Yesus terjadi tepatnya pada hari Jumat pukul 05.00 sore dan penyembelihan domba yang dilakukan oleh tradisi Yahudi terjadi pada hari Jumat pukul 05.00 sore. Berdasarkan hal inilah, gereja kemudian memaknai Yesus sebagai Anak Domba Paskah yang sungguh dan benar, yang akan datang untuk menghapus dosa dunia. ${ }^{15}$

Melalui peringatan ini, gereja dapat mengalami perubahan berupa pembaruan sikap hidup yang lama menjadi hidup yang bersandar pada Allah. Gereja memaknai perayaan Perjamuan Kudus sebagai peringatan akan kematian Kristus yang melaluinya iman kita makin dikuatkan, sebagai sebuah harapan akan kehidupan yang baru dan juga sebagai penyaksian akan harapan yang dinyatakan oleh Tuhan. Dengan kata lain, peringatan ini bukan hanya terkait pada penderitaan Tuhan melainkan juga kemenanganNya atas maut. ${ }^{16}$ Penyaksian inilah yang membuat kita makin didorong untuk memuliakan Tuhan Allah di dalam hidup kita. Oleh sebab itu, perjamuan bukan hanya melihat tentang peristiwa-peristiwa yang terjadi, tetapi juga membawa kemungkinan untuk melihat kenyataan yang terjadi di masa kini dan menaruh pengharapan pada masa depan untuk memperoleh kehidupan yang baru. ${ }^{17}$ Pemaknaan Perjamuan Kudus sebagai peringatan, pengharapan dan penyaksian memperlihatkan bahwa untuk mencapai ketiga makna tersebut membutuhkan waktu yang panjang sehingga Gereja Protestan memahami Pejamuan Kudus sebagai ritus yang luar biasa.

Dalam Perjanjian Baru, gereja mula-mula hingga saat ini masih melaksanakan perintah Yesus sebelum Ia ditangkap. Perintah Yesus saat itu ialah merayakan perjamu-

\footnotetext{
${ }^{12}$ H. H. Rowley, Ibadat Israel Kuno (Jakarta: BPK Gunung Mulia, 2004), 95.

${ }^{13}$ Rasid Rachman, Hari Raya Liturgi: Sejarah dan Pesan Pastoral Gereja (Jakarta: BPK Gunung Mulia, 2005), 12.

${ }^{14}$ Harls Evan Siahaan, "Mengajarkan Nasionalisme Lewat Momentum Perayaan Paskah : Refleksi Kritis Keluaran 12 : 1-51," DUNAMIS (Jurnal Teologi dan Pendidikan Kristiani) 1, no. 2 (2017): 140-155.

${ }^{15}$ C. J. Den Heyer, Perjamuan Tuhan, 100.

${ }^{16}$ H. Enklaar, Baptisan Massal dan Pemisahan Sakramen-sakramen (Jakarta: BPK Gunung Mulia, 1978), 141.

17 C. J. Den Heyer, Perjamuan Tuhan, 56.
} 
an Tuhan atau Perjamuan Kudus. Dengan kata lain, Perjamuan Kudus terjadi saat Yesus melakukan perpisahan dengan murid-murid-Nya. Yesus memecah-mecahkan roti dan minum anggur sebagai tanda peringatan atau dalam bahasa Yunani anamnesis. ${ }^{18}$ Perayaan ini menjadi sebuah peringatan kepada murid-murid-Nya ketika Yesus berkata “Perbuatlah ini menjadi peringatan akan Aku!” Dengan demikian, perjamuan kudus dapat diartikan sebagai sebuah upacara atau ritus yang bersifat peringatan. ${ }^{19}$

Berbeda dengan injil sinoptik yang memahami perjamuan kudus sebagai ritus yang sakral, jemaat di Korintus justru merayakan perjamuan kudus tanpa melakukan persiapan yang baik. Jemaat di Korintus merayakan perjamuan kudus dengan cara berkumpul bersama, makan dan minum bersama demi untuk memenuhi rasa lapar dan haus mereka. Dengan kata lain, mereka merayakan perjamuan kudus selayaknya merayakan pesta pora dan bagi siapa yang datang terlambat tidak akan memperoleh makan dan minum. ${ }^{20}$ Tindakan mereka seperti ini kemudian ditentang oleh Paulus karena Paulus menempatkan Perjamuan Kudus dalam konteks suatu persekutuan di meja makan. Paulus mengartikan Perjamuan Kudus dalam persekutuan dengan mengatakan bahwa roti yang dipecah-pecahkan adalah persekutuan dalam tubuh Kristus, dan cawan pengucapan syukur adalah persekutuan dalam darah Kristus. Dengan demikian, ketika setiap orang percaya turut terlibat dalam perayaan Perjamuan Kudus dapat berarti bahwa mereka juga terlibat dalam pengorbanan Kristus. ${ }^{21}$

\section{Pandangan Reformator tentang Sakramen Perjamuan Kudus}

Pada gereja-gereja reformasi, ada tiga reformator yang memiliki pemahaman terhadap sakramen Perjamuan Kudus, yakni Martin Luther, Zwingli, dan John Calvin. Pemahaman yang berebda tentu saja memiliki pemaknaan yang berbeda. Menurut Martin Luther, sakramen adalah sebuah tanda yang lahiriah dan apa yang ditandai bersifat batiniah dan rohani. ${ }^{22}$ Tanda tersebut diberikan oleh Allah melalui sentuhan para imam. ${ }^{23}$ Dalam perayaan sakramen Perjamuan Kudus Kristus benar-benar hadir. Namun bagi Luther, kehadiran Kristus tidaklah merubah substansi roti dan anggur. Persatuan antara Kristus dan orang percaya dapat terjadi melalui iman dan bukan melalui perubahan ajaib yang menjadikan roti dan anggur sebagai tubuh dan darah Kristus. ${ }^{24}$ Luther juga memaknai Perjamuan Kudus sebagai suatu pemberiaan, suatu karunia atau beneficium

\footnotetext{
18 Dieter Becker, Pedoman Dogmatika: Suatu Kompendium Singkat (Jakarta: BPK Gunung Mulia, 2012), 166.

${ }^{19}$ Ebenhaizer I. Nuban Timo, Umat Allah di Tapal Batas (Salatiga: Alfa Design, 2011), 211.

20 Ulrich Beyer, Garis-garis Besar Eskatologi dalam Perjanjian Baru (Jakarta: BPK Gunung Mulia, 2003), 31.

${ }^{21}$ Donald Guthrie, Teologi Perjanjian Baru 3: Eklesiologi, Eskatologi, Etika (Jakarta: BPK Gunung Mulia, 2009), 86.

${ }^{22}$ Ch, J. L. Abineno, Perjamuan Malam Menurut Ajaran Para Reformator (Jakarta: BPK Gunung Mulia, 1990), 21.

23 Ibid., 23.

24 Christian de Jonge, Apa itu Calvinisme? (Jakarta: BPK Gunung Mulia, 2011), 217.
} 
yang Allah berikan kepada manusia. ${ }^{25}$ Oleh sebab itu, Luther menekankan bahwa Perjamuan Kudus dirayakan bukan karena Allah yang membutuhkannya tetapi karena kita sendiri yang lebih membutuhkannya.

Berbeda dengan pemahaman Luther, menurut Zwingli, sakramen bukanlah sesuatu yang suci, yang dapat membebaskan manusia dari dosa-dosanya. Sakramen adalah sebuah kewajiban yang mendatangkan jaminan, janji atau sumpah yang dapat mengingatkan orang-orang percaya untuk selalu setia dalam pelayanannya. ${ }^{26}$ Zwingli juga memaknai sakramen Perjamuan Kudus sebagai ekaristi atau pengucapan syukur. ${ }^{27}$ Dalam perayaannya, Zwingli menerima kehadiran Kristus dalam arti rohani. Artinya bahwa Kristus dapat hadir dalam setiap roh manusia apabila ia percaya kepada Kristus. ${ }^{28}$ Elemen yang digunakan saat perjamuan ialah roti dan anggur sebagai simbol yang digunakan untuk memperingati pengorbanan Kristus. Zwingli juga berpendapat bahwa Perjamuan Kudus merupakan suatu hidangan persaudaraan dan peringatan dari jemaat Kristen sehingga diperuntukan kepada siapa saja, entah itu orang tua atau pun anak-anak karena Perjamuan dirayakan sebagai bentuk persaudaraan.

Selain Luther dan Zwingli, Calvin memahami sakramen sebagai tanda dan meterai yang diberikan Allah kepada kita dengan janji-janji-Nya akan kehendak yang baik dan untuk menopang segala kelemahan kita. ${ }^{29}$ Tanda yang kelihatan dari apa yang Allah berikan kepada kita dalam perayaan Perjamuan Kudus ialah roti dan anggur. ${ }^{30}$ Calvin berpendapat bahwa sakramen Perjamuan Kudus ditetapkan oleh Allah dan substansinya ialah Yesus Kristus. Tujuan Allah menetapkan Perjamuan Kudus kepada kita, yaitu untuk menandai dan memeteraikan janji-janji Allah yang ada di dalam firman-Nya; untuk melatih kita agar kita percaya pada kebaikan-Nya yang telah diberikan kepada kita; dan untuk mengarahkan kita untuk hidup yang suci dan saleh agar dapat mencerminkan tubuh Kristus. ${ }^{31}$ Dalam perayaan Perjamuan Kudus, Kristus benar-benar hadir dan kehadiran-Nya menjadikan makanan jasmani berubah menjadi makanan rohani. Artinya bahwa setiap orang percaya dapat memperoleh penguatan jiwa karena mereka telah dipersatukan dengan Kristus. ${ }^{32}$

\section{Masa-Masa Persiapan Menjelang Perjamuan Kudus Menurut Para Reformator}

Tidak hanya demikian, para reformator ini juga memiliki pemahaman tentang persiapan yang dilakukan menjelang perayaan Perjamuan Kudus. Menurut Luther, ada dua hal yang harus diperhatikan sebelum mengikuti Perjamuan Kudus, yaitu penyesalan

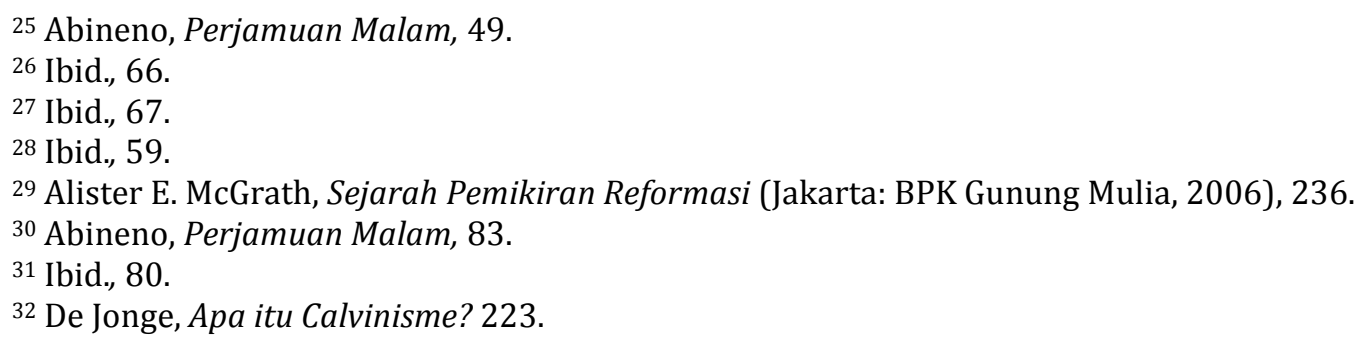


dan percaya. ${ }^{33}$ Penyesalan yang dimaksudkan ialah menyesali dosa-dosa yang telah dilakukannya, seperti kecenderungan untuk membenci, untuk memarahi, untuk menyombongkan diri, untuk melakukan hal-hal yang kotor dan bahkan memiliki perasaan tidak layak untuk mengikuti Perjamuan Kudus. Menurut Luther, setiap orang percaya mengikuti Perjamuan Kudus bukan karena ia suci, saleh dan benar tetapi karena ia benar-benar percaya pada firman Allah dan percaya bahwa Allah yang memerintah kita untuk turut merayakannya. Akan tetapi, Allah juga menginginkan untuk adanya penyesalan akan dosa-dosa yang dilakukan. Dengan demikian, Luther menasehatkan agar setiap orang yang akan mengikuti Perjamuan Kudus harus mengisi hari-hari sebelum perayaan Perjamuan Kudus dengan berdoa, percaya pada firman Tuhan dan membuang semua rasa benci terhadap sesamanya. ${ }^{34}$ Dalam situasi seperti ini, Tuhan memberikan sakramen Perjamuan Kudus sebagai alat untuk menyelamatkan kita dari dosa-dosa yang telah kita lakukan.

Selain Luther, Calvin juga memiliki pemahaman yang sejalan dengan persiapan Perjamuan Kudus. Menurut Calvin, setiap orang yang turut merayakan Perjamuan Kudus harus melakukan persiapan. Apabila kita merayakan Perjamuan Kudus tanpa persiapan, maka secara tidak langsung kita telah menyalahgunakannya dan menodai apa yang telah dikuduskan oleh Allah. Persiapan yang dimaksudkan ialah penyelidikan diri. Calvin mengharuskan untuk menyelidiki apakah ada hal-hal yang tidak baik di dalam hati kita? Dan apakah kita benar-benar percaya kepada Yesus Kristus? ${ }^{35}$ Penyelidikan ini tidak dapat dirasakan apabila kita tidak berani mengaku dosa-dosa kita dihadapan-Nya. Ketika kita berani untuk mengaku dosa-dosa kita, maka kita akan merasa malu dan membenci serta menghukum diri kita sendiri. Calvin juga menasihatkan untuk mengisi masa-masa penantian perayaan Perjamuan Kudus setelah penyelidikan diri dengan cara berdoa, tetap percaya kepada satu Tuhan dan bukan kepada makhluk yang lainnya, mengakui dan menerima Kristus sebagai satu-satunya kebenaran yang menyelamatkan kita, serta membuang segala tindakan yang tidak sesuai dengan ajaran Tuhan seperti pelacuran, kesombongan, keburukan, dan kejahatan-kejahatan lain. ${ }^{36}$ Dengan kata lain, di dalam Kristus hanya ada kesucian, kebaikan, kasih, dan hal-hal baik lainnya.

Menurut Calvin, anggota gereja yang dapat mengikuti Perjamuan Kudus hanyalah orang-orang yang mengaku iman percayanya kepada Tuhan. Selain itu, orang-orang yang mengaku dosa-dosanya kepada Tuhan juga dapat diberikan kesempatan untuk mengikuti perayaan Sakramen Perjamuan Kudus yang di dalamnya, mereka dipersatukan dengan Kristus. Oleh sebab itu, salah satu ajaran yang sangat ia tekankan adalah disiplin gereja. Disiplin gereja adalah penegakan ketertiban dan pengawasan

\footnotetext{
33 Abineno, Perjamuan Malam, 20.

34 Ibid., 21.

35 Ibid., 86.

36 Ibid., 88.
} 
ajaran maupun perilaku yang dilakukan secara ketat. ${ }^{37} \mathrm{Hal}$ ini dilakukan dengan tujuan untuk mengawasi kehidupan setiap orang percaya supaya tetap menjadi kudus. Dalam perayaan Perjamuan Kudus, seringkali ada alasan yang dikemukakan sebagai alasan untuk tidak mengikuti Perjamuan Kudus, yaitu merasa diri tidak layak dan tidak ingin menyatu dengan orang-orang berdosa yang belum bertobat. Kedua alasan ini ditolak secara utuh oleh Calvin. Menurut Calvin, ketika seseorang merasa tidak layak untuk mengikuti Perjamuan Kudus, maka secara tidak langsung ia telah mengasingkan dirinya dari Allah karena ia tidak berani untuk mengaku dosa-dosanya. ${ }^{38}$ Orang-orang seperti inilah yang akan dikenakan disiplin gereja sehingga tidak diperbolehkan untuk turut terlibat di dalam perayaan Perjamuan Kudus. ${ }^{39}$

\section{Makna Perjamuan Kudus menurut GPM}

GPM mengartikan sakramen Perjamuan Kudus sebagai suatu jamuan yang dikhususkan untuk memperingati peristiwa kematian dan kebangkitan Yesus. perjamuan kudus dibuat untuk memelihara iman orang percaya bahwa manusia dana lam semesta ini telah diselamatkan oleh Allah melalui peristiwa kematian dan kebangkitan Yesus. ${ }^{40}$ Bagi GPM, sakramen perjamuan kudus mengandung beberapa makna, yakni pertama, pengucapan syukur atas kasih karnuia Allah yang menyelamatkan manusia dan alam semesta dari kuasa dosa dan maut; kedua, peringatan orang-orang percaya pada peristiwa kematian dan kebangkitan Yesus (Luk. 22:19; 1Kor. 11:24-25); ketiga, persekutuan orang-orang percaya dengan Yesus dan orang-orang percaya satu sama lain (1Kor. 10:16,17); dan keempat, eskatologis yaitu menunjuk pada adanya keselamatan yang tersedia di akhir zaman (Mrk. 14:15; 1Kor. 11:26; Yoh. 1:29,36; 19:36; 1Kor. 5:7; 1Ptr. 1:19; Why. 5:6; 12:11). ${ }^{41}$

Sebelumnya, GPM hanya melaksanakan sakramen perjamuan kudus sebanyak dua kali dalam setahun, yaitu perjamuan di bulan April sebagai perjamuan Jumat Agung dan perjamuan di bulan Oktober sebagai perjamuan Oikumene. Akan tetapi, seiring dengan perkembangan yang terjadi maka melalui sidang Sinode, pelaksanaan sakramen Perjamuan Kudus ditetapkan empat kali dalam satu tahun, yaitu pada Minggu pertama di bulan Januari sebagai perjamuan di awal tahun yang akan melandasi seluruh kehidupan di sepanjang tahun, perjamuan di bulan April sebagai perjamuan Jumat Agung, perjamuan di bulan Juli sebagai perjamuan di pertengahan tahun dan perjamuan di bulan Oktober sebagai perjamuan Oikumene.

37 Jan S. Aritonang, Berbagai Aliran di dalam dan di sekitar Gereja (Jakarta: BPK Gunung Mulia, 2008),

38 Abineno, Perjamuan Malam, 91.

${ }^{39}$ Niftrik dan Boland, Dogmatika Masa, 456.

${ }^{40}$ Ajaran Gereja GPM Nomor 247, Hasil Sidang Sinode GPM Ke-37.

41 Ibid. 


\section{Makna Perhadliran dalam Sakramen Perjamuan Kudus}

Sebelum pelaksanaan sakramen perjamuan kudus, GPM melaksanakan perkunjungan pastoral kepada setiap keluarga dengan pergumulan kehidupan mereka yang berbedabeda. Dalam perkunjungan tersebut, secara tidak langsung pendeta dan majelis jemaat mengundang anggota keluarga yang telah sidi untuk mengikuti perjamuan kudus. Setelah perkunjungan pastoral kepada setiap keluarga, GPM melaksanakan ibadah perhadliran tepatnya seminggu sebelum pelaksanaan Perjamuan Kudus. Pelaksanaan sakramen perjamuan kudus sebanyak empat kali setahun menunjukan bahwa ibadah perhadliran juga dilakukan sebanyak empat kali setahun. ${ }^{42}$

Secara historis, istilah perhadliran yang digunakan GPM untuk persiapan perjamuan kudus tidak diketahui dengan pasti asal-usulnya. Namun ditemukan bahwa kata perhadliran yang selama ini digunakan GPM merupakan hasil adopsi dari proses masuknya Injil ke Maluku oleh VOC dan Belanda. ${ }^{43}$ Kenyataan ini memberi gambaran bahwa penggunaan istilah perhadliran oleh GPM masih terkesan kabur, karena tidak didasari oleh sebuah sejarah yang pasti. Ketidakjelasan sejarah seperti ini yang kemudian akan menyulitkan proses pemahaman terhadap perhadliran itu sendiri.

Dalam Ajaran Gereja GPM, kemungkinan besar kata perhadliran berasal dari bahasa Arab yakni hadler yang artinya layak. Akan tetapi ada juga yang mengatakan bahwa kata ini dibentuk dari kata dasar hadir. ${ }^{44}$ Oleh sebab itum tidak diketahui dengan pasti asal-usul kata tersebut. Itulah sebabnya ada yang mengusulkan agar perhadliran sebaiknya diganti saja dengan Minggu Persiapan Diri Memasuki perjamuan kudus. GPM menggunakan istilah perhadliran untuk memberi penekanan khusus pada persiapan umat menghadapi perjamuan kudus. Umat harus menguji diri, apakah mereka layak mengambil persekutuan dengan Yesus dan umat-Nya untuk makan dan minum bersama-sama dalam perjamuan kudus (1 Kor. 11:27-29). Pada prinsipnya orang yang telah menerima undangan dan telah menguji diri sendiri, layak mengikuti perjamuan kudus. Tetapi bila karena alasan tertentu seseorang tidak mengikuti perhadliran, tetapi rindu dan merasa layak mengikukti perjamuan kudus, maka ia harus memberitahukannya kepada majelis jemaat. ${ }^{45}$

Pelaksanaan perhadliran telah dilakukan oleh GPM sejak dahulu dengan beragam pemahaman. Perhadliran merupakan tradisi GPM yang dilakukan untuk mempersiapkan anggota-anggota jemaat yang telah Sidi untuk mengikuti Sakramen Perjamuan Kudus. ${ }^{46}$ Perhadliran merupakan sebuah kebiasaan gereja yang dilakukan oleh gerejagereja Calvinis yang bersifat presbiterial sinodal. ${ }^{47}$ Akan tetapi, kebiasaan gereja dalam

\footnotetext{
42 Hasil Wawancara dengan Pdt. E. M., 26 Agustus 2018, 21.00 WIT.

${ }^{43}$ Hasil Wawancara dengan Pdt. J. L., 21 Agustus 2018, 13.15 WIT.

${ }^{44}$ Ajaran Gereja GPM Nomor 254, Hasil Sidang Sinode GPM Ke-37.

${ }^{45}$ Ajaran Gereja GPM Nomor 255, Hasil Sidang Sinode GPM Ke-37.

${ }^{46}$ Hasil Wawancara dengan Pdt. E. M., 26 Agustus 2018, 21.00 WIT \& Pdt. J. L., 21 Agustus 2018,

${ }^{47}$ Hasil Wawancara dengan Pdt. H. F, 20 Agustus 2018, 10.00 WIT.
} 13.15 WIT. 
mempersiapkan anggota jemaat untuk mengikuti Perjamuan Kudus memiliki penyebutan yang berbeda-beda. Selain itu, perhadliran juga merupakan sebuah momen puncak dari peneguhan sidi gereja, yang telah menyelesaikan pendidikan katekisasi dan mengaku iman percaya kepada Tuhan dalam ibadah khusus peneguhan anggota sidi gereja baru. ${ }^{48}$

Pemahaman-pemahaman para Pendeta GPM ini sejalan dengan pandangan Marthin Luther yang menyatakan bagaimana seharusnya anggota jemaat mempersiapkan diri untuk mengikuti Perjamuan Kudus. Pandangan Luther didukung pula oleh Calvin yang menyatakan bahwa Perjamuan Kudus tanpa persiapan sama dengan menyalahgunakan dan menodai apa yang dikuduskan Allah. Dengan demikian, Perjamuan Kudus sebagai salah satu sakramen gerejawi yang sakral tidak dapat dilaksanakan begitu saja tanpa adanya persiapan diri. Persiapan tersebut menuntut adanya kerelaan hati untuk bertobat, pengakuan akan Yesus Kristus sebagai Tuhan dan patuh pada perintahperintahNya. Oleh sebab itu, kesadaran akan pentingnya persiapan diri sebelum mengikuti Perjamuan Kudus, dimaksudkan agar setiap anggota jemaat yang hendak mengikuti Perjamuan Kudus benar-benar memiliki pemahaman dan pemaknaan yang benar terhadap pelaksanaan Perjamuan Kudus yang akan diikuti.

Pelaksanaan ibadah perhadliran memiliki dua tujuan, yaitu pertama, untuk mempersiapkan umat Tuhan sedini mungkin agar dapat mempersiapkan diri dan hati untuk mengambil bagian di dalam pelaksaan perjamuan kudus. Kedua, untuk memonitor anggota jemaat yang menyatakan kesiapannya untuk mengikuti perjamuan kudus. Hal ini merupakan sebuah keuntungan bagi pemimpin gereja untuk dapat melakukan pendekatan secara langsung melalui percakapan pastoral dengan anggota jemaat yang telah sidi namun tidak berdiri untuk menyatakan kesiapannya dalam mengikuti perjamuan kudus. Berdasarkan hal tersebut, GPM memaknai ibadah perhadliran sebagai sebuah tradisi yang wajib diikuti apabila umat ingin untuk mengambil bagian di dalam sakramen perjamuan kudus. Ibadah perhadliran membutuhkan kesiapan dari setiap umat, terkhususnya kesiapan hati dan pikiran agar tidak lagi terjebak di dalam dosa-dosa duniawi.

Pelaksanaan perhadliran oleh GPM dilakukan bersamaan dengan pelaksanaan Ibadah Minggu Jemaat, dengan kata lain Ibadah perhadliran turut dimasukan sebagai unsur liturgi Ibadah Minggu Jemaat. Secara liturgis, Ibadah perhadliran tidak memiliki liturgi khusus, namun dalam pelaksanaan perhadliran, anggota jemaat diharuskan menjawab empat pertanyaan perhadliran. Mengingat minimnya literatur dan informasi terkait pelaksanaan Perhadliran, maka penulis mencoba mengkaji dimensi persiapan

48 Elifas T. Maspaitella, Perjamuan Kudus GPM, Kutikata Blog, 26 April 2011, diakses pada 21 Agustus 2018, http://kutikata.blogspot.co.id/2011/04/perjamuan-kudus-gpm.html. 
diri atau perhadliran yang dilakukan oleh GPM sebelum pelaksanaan perjamuan kudus ditinjau dari empat pertanyaan Perhadliran yang dipakai:

1. Apakah saudara-saudara percaya dengan segenap hati bahwa pengajaran yang benar dan sempurna yang membina kepada keselamatan berdasarkan Firman Allah yang semuanya hanya terdapat di dalam Alkitab?

Pertanyaan pertama yang digunakan GPM pada saat perhadliran mengandung makna bahwa Alkitab menjadi pusat pengajaran GPM. Segala pengajaran dan nasehat telah tertuang di dalam Alkitab, sehingga tidak ada satu pun pengajaran yang benar dan sempurna yang membina kepada keselamatan di luar Alkitab.

2. Apakah dengan segenap hati saudara-saudara percaya bahwa justru oleh karena dosa, maka kita patut dimusnahkan oleh Allah sebab itu kita harus menyesali akan diri-diri kita?

Pertanyaan kedua mengandung makna pengakuan dan penyesalan dosa. Melalui pertanyaan kedua umat diingatkan kembali bahwa mereka adalah orang-orang berdosa dan akibat dosa maka umat patut dimusnahkan. Akan tetapi, penggunaan kata dimusnahkan dalam pertanyaan ini sebaiknya tidak digunakan karena dosa tidak membuat Allah memusnahkan manusia dan dunia melainkan dosa mengakibatkan hubungan manusia dengan Allah menjadi jauh dan kejauhan itu diluruskan oleh Yesus melalui pengorbananNya di kayu Salib. Oleh sebab itu, kata yang dapat digunakan untuk menggantikan kata dimusnahkan ialah kata dihukum.

3. Apakah saudara-saudara mengaku bahwa berdasarkan kasih Allah yang tidak berhingga, sudahlah Ia mengaruniakan kita anak-Nya yang tunggal Tuhan Yesus Kristus yang dengan rela telah memecahkan tubuhNya dan menumpahkan darahNya khusus untuk pengampunan dosa kita, pengorbanan mana patut disambut dengan hati yang beriman?

Pertanyaan ketiga mengandung akta pengakuan bahwa pengampunan dosa dan keselamatan yang telah diterima oleh umat didasarkan atas Kasih Allah bagi dunia ini dengan cara mengorbankan AnakNya yang tunggal yaitu Yesus Kristus (Yoh. 3:16). Pada akta pengakuan ini keselamatan yang diberikan oleh Allah bersifat universal dan bukan menjadi milik sebagian umat saja.

4. Apakah saudara-saudara berniat dengan hati yang tulus ikhlas sesuai panggilan kita berdasarkan Baptisan Kudus dan pengakuan umat untuk menyerahkan hidup dipengaruhi oleh Roh Kudus agar bertambah-tambah di dalam kasih, iman dan pengharapan serta hidup dalam persekutuan yang benar sebagaimana patut bagi segala orang percaya?

Pertanyaan keempat memberi penekanan pada kesediaan dan tekad umat untuk hidup di dalam Tuhan, dengan cara memberi hidup dituntun Roh Kudus, serta hidup dalam iman dan pengharapan.

Berdasarkan kajian terhadap empat pertanyaan perhadliran yang digunakan oleh GPM, maka pertanyaan-pertanyaan tersebut mengandung empat unsur yang saling berkaitan yakni unsur kepercayaan, keyakinan, pengakuan dan tekad untuk hidup di 
dalam Tuhan. Keempat unsur ini masih bersifat umum dan kurang mengandung unsurunsur persiapan diri. Menurut penulis, dalam ibadah perhadliran yang dibutuhkan ialah liturgi dan pertanyaan-pertanyaan yang berfokus pada persiapan diri jemaat, agar jemaat dapat diarahkan untuk lebih memahami dan memaknai makna pengorbanan Yesus. Unsur persiapan diri hanya nampak dan sangat kontekstual bagi umat dalam mempersiapkan diri, terlihat pada pertanyaan keempat yakni umat diminta untuk menyerahkan diri dituntun oleh Roh Kudus. Mengingat Perjamuan Kudus merupakan ibadah khusus yang membutuhkan persiapan diri, maka ibadah perhadliran yang dilakukan oleh GPM haruslah menjadi sarana yang tepat untuk mengantarkan umat memasuki Sakramen Perjamuan Kudus.

\section{Kesimpulan}

Perjamuan kudus merupakan tanda peringatan akan pengorbanan Yesus Kristus yang rela mati di tiang kayu salib untuk menebus dosa umat manusia. Keikutsertaan umat percaya dalam mengikuti Perjamuan Kudus diawali dengan proses persiapan diri yang dalam tradisi GPM disebut perhadliran. Secara historis, pengertian perhadliran tidak diketahui dengan pasti, namun GPM melaksanakan ibadah perhadliran dengan tujuan untuk mempersiapkan umat sebelum mengikuti Perjamuan Kudus. Ibadah perhadliran dalam tradisi GPM tidak memiliki tata ibadah khusus, tetapi disisipkan sebagai salah satu unsur dalam Tata Ibadah Minggu, yang mana dalam pelaksanaannya umat diminta untuk menjawab empat pertanyaan perhadliran. Selain itu dalam pelaksanaan ibadah perhadliran juga ditemukan bahwa pemberitaan Firman Tuhan menjadi tidak efektif karena pemberitaan Firman pada ibadah Minggu digunakan juga sebagai bahan pemberitaan Firman untuk ibadah perhadliran, sehingga ibadah perhadliran tidak jauh berbeda dengan ibadah Minggu.

Perhadliran yang dilakukan oleh GPM dalam pelaksanaan Sakramen Perjamuan Kudus mengandung tiga makna utama, yakni: Pertama, Makna persiapan diri, mengandung pengertian bahwa setelah mengikuti perhadliran umat percaya yang akan mengikuti Perjamuan Kudus dituntut untuk mampu mempersiapkan diri melalui cara hidup yang berkenan kepada Allah. Kedua, Makna pengakuan, mengandung pengertian bahwa dalam pelaksanaan perhadliran umat percaya diharuskan menjawab empat pertanyaan perhadliran, mengaku bahwa karena dosa-dosa kita patut dihukum dan hanya melalui pengorbanan dan kerelaan Yesus maka kita semua telah diselamatkan. Ketiga, Makna perjanjian, mengandung pengertian bahwa jawaban yang telah kita berikan kepada Allah melalui empat pertanyaan perhadliran, menjadi tanda pengungkapan janji kita kepada Allah untuk tidak lagi hidup di dalam dosa, tetapi hidup di dalam pengharapan bersama Yesus. 


\section{Referensi}

Abineno, J. L. Ch. Pemberitaan Firman Pada Hari-hari Khusus. Jakarta: BPK Gunung Mulia, 1981.

. Perjamuan Malam Menurut Ajaran Para Reformator. Jakarta: BPK Gunung Mulia, 1990.

Ajaran Gereja GPM, Hasil Sidang Sinode GPM Ke-37.

Aritonang, Jan S. Berbagai Aliran di dalam dan di sekitar Gereja. Jakarta: BPK Gunung Mulia, 2008.

Becker, Dieter. Pedoman Dogmatika: Suatu Kompendium Singkat. Jakarta: BPK Gunung Mulia, 2012.

Beyer, Ulrich. Garis-garis Besar Eskatologi dalam Perjanjian Baru. Jakarta: BPK Gunung Mulia, 2003.

Calvin, Yohanes. Institutio: Pengajaran Agama Kristen. Jakarta: BPK Gunung Mulia, 2008.

Denzin, Noman K. dan Lincoln, Yonna S. The Sage Handbook of Qualitative Research I. Yogyakarta: Pustaka Pelajar, 2011.

Den Heyer, C. J. Perjamuan Tuhan: Studi mengenai Paskah dan Perjamuan Kudus bertolak dari penafsiran dan Teologi Alkitabiah. Jakarta: BPK Gunung Mulia, 1994.

Enklaar, H. Baptisan Massal dan Pemisahan Sakramen-sakramen. Jakarta: BPK Gunung Mulia, 1978.

Guthrie, Donald. Teologi Perjanjian Baru 3: Eklesiologi, Eskatologi, Etika. Jakarta: BPK Gunung Mulia, 2009.

Himpunan I Liturgi Gereja Protestan Maluku, Ambon: Sekretariat Umum Gereja Protestan Maluku, 2011.

Maspaitella, Elifas T. Perjamuan Kudus GPM, Kutikata Blog, 26 April 2011. Akses pada 3 Februari 2018. http://kutikata.blogspot.co.id/2011 0401 archive.html

McGrath, Alister E. Sejarah Pemikiran Reformasi. Jakarta: BPK Gunung Mulia, 2006. Moleong, Lexy J. Metodologi Penelitian Kualitatif. Bandung: Remaja Rosdakaria, 1998. Munthe, A. Tema-tema Perjanjian Baru. Jakarta: BPK Gunung Mulia, 2006.

Nuban Timo, Ebenhaizer I. Umat Allah di Tapal Batas. Salatiga: Alfa Design, 2011.

Rachman, Rasid. Hari Raya Liturgi: Sejarah dan Pesan Pastoral Gereja. Jakarta: BPK Gunung Mulia, 2005.

Rowley, H. H. Ibadat Israel Kuno. Jakarta: BPK Gunung Mulia, 2004.

Siahaan, Harls Evan. "Mengajarkan Nasionalisme Lewat Momentum Perayaan Paskah : Refleksi Kritis Keluaran 12 : 1-51." DUNAMIS (Jurnal Teologi dan Pendidikan Kristiani) 1, no. 2 (2017): 140-155.

Soedarmo, R. Ikhtisar Dogmatika. Jakarta: BPK Gunung Mulia, 2009.

Walker, Peter. In The Steps Of Jesus. Yogyakarta: Kanisius, 2010. 